International Journal of Engineering \& Technology, $7(3.34)(2018) 58-60$
SPC
Website: $w$ ww.sciencepubco.com/index.php/IJET
Research paper

\title{
A Review of Mobile Oil Skimmer
}

\author{
Sathiyamoorthy $\mathrm{V}^{1^{*}}$, Arumugam $\mathrm{K}^{2}$ Arun Pragathish $\mathrm{M}^{3}$, Barath B.N $\mathrm{N}^{4}$, Baskar $\mathrm{M}^{5}$, Balamurugan $\mathrm{S}^{6}$ \\ ${ }^{1,5}$ Faculty, ${ }^{2,3,4}$ Students, Department of Mechanical Engineering, Vel Tech High Tech Dr.Rangarajan Dr.Sakunthala Engineering \\ college, Avadi -600 062, Tamil Nadu, India. \\ ${ }^{6}$ Faculty of mechanical engineering, Mahendra college of engineering, Salem, Tamil nadu, India. \\ *Corresponding author E-mail: drvsathiyamoorthy@gmail.com
}

\begin{abstract}
This project work is implemented based on the public issue which has overcome by our people on January 2017 at Ennore Chennai, Tamilnadu, India. The oil skimmer is used to separate oil, from mixtures of aqua and oil. It causes highly acidic alkaline and salty environment remains a great challenge to aquatic organisms and also pollutes the coastal areas. Every year 706 million gallons of waste oil enters the water resources and pollute the environment. Sea water has been polluted due to oil spillage; it also affects the water bodies. If the oil spill increases it results in serious damage to environment. About $90 \%$ of contaminated oil can be removed by continuous separation of oil by skimmer belt. This set-up uses polyurethane belt, bearing, supporting L-angle frame, EN 19 Rod \& Scraper. This work implemented to improve the separation efficiency of the skimmer belt at manual speeds.
\end{abstract}

Keywords: Skimmer belt, Bearing, Supporting L-angle frame, EN 19 Rod, Scraper and Oil properties.

\section{Introduction:}

An oil skimmer is a device that is designed to remove oil floating on a liquid surface. Based on the specific design they are used for a various applications such as oil spill response, as a part of oily water treatment systems, removing oil from the coolant and aqueous part washers and collecting fats, mixed oils and greases in wastewater treatment.

The types of approaches which are used to filter the oil content from water by using oil skimmer belt. It is a mechanical device that helps in removing floating oil and tiny greasy particles from water [1]. In modern world, rapid and quick working is more important with new idea. The new invention of machines that are used to reduce the problems in the world is necessary [2]. Pollution has created lot of issues in day- to-day life. In that water pollution is uncontrollable. Due to water pollution, the tourism, fishing and aquatic organisms are greatly affected. An oil skimmer is a device that is designed to remove oil floating on a liquid surface. Oil is one of the most important raw materials for synthetic polymer and chemicals [3]. The release of oil into natural environment is termed as oil spill or spillage. The oily material in the contaminated water can be removed by using belt in the oil skimmer. Since, oil is lighter than the water they can be easily stuck to the belt of the skimmer. Oil skimmers are very effective tool for removing dirty, uncleared and sticky fluids that are present in the ocean water. Oil spills over the sea, river and water resources becomes a serious issue to the public welfare. The separated water can achieve the level of purity and level of $\mathrm{Ph}$ for re-use. The water is mainly used for cutting purpose and drilling purpose. Separation of oily and greasy particles based upon the specific gravity, viscosity etc. Generally mechanical belt skimmers operate simply by lifting the oil from the mixed water surface to the collection point [4].
The function of oil skimmer, its various design aspects and performance. All the results of experimental studies indicate that slight design improvement of typical oil skimmers towards to include additional belt shaft and use of belt with steel material instead of rope; significantly improve the oil recovery rate and efficiency. This paper has illustrated the practical overview of oil spills by using current oil spill technology.

Further extensive research \& testing can improve the existing techniques and equipment to have better control for oil recovery exercise. A set of experiments had been conducted by using various oils and different materials of belt to understand the oil recovery performance and viscosity deviation of oils before and after separation [5].

These oil spills have caused a great collision on ecological life around the spillage. He had conclude that the oil spillage is not only harmful but also result in loss of lives and money. So the recovery of spilled oil is very necessary. He studied various oil skimmer belts and their properties $[6,8]$.

Prof. P.A. Patil et. al. had concluded that the separation of oil is based on surface tension, specific gravity and viscosity. He studied the operation of oil skimmer on various positions of the belt like inclined, vertical, horizontal [7].

\section{Experimental Set-Up:}

\subsection{Shaft:}

It is high quality material EN19. low cost with dc geared motor. Generally it is a magnetic rod and it is very hard to cut. Two shafts are connected to the frame. One shaft at top of the frame $490 \mathrm{~mm}$ \& other shaft at bottom of the frame $390 \mathrm{~mm}$. step turning and Vgroove operations are done. 


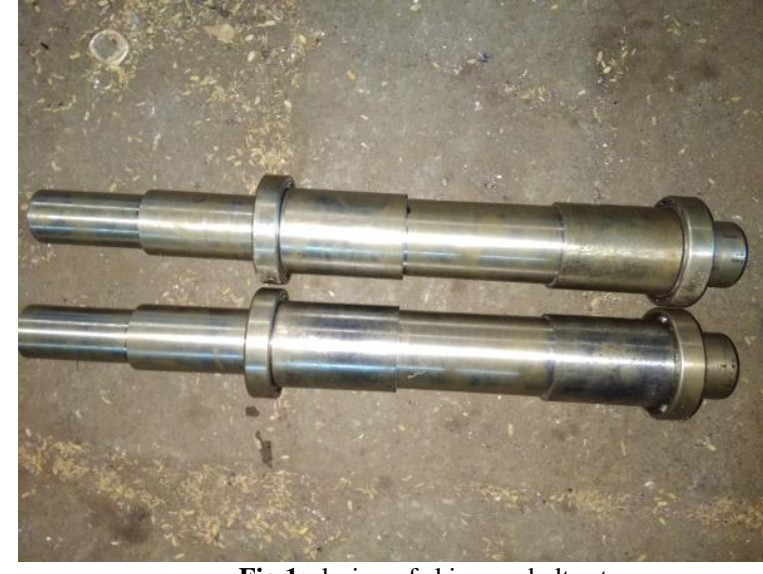

Fig.1: design of skimmer belt setup

\subsection{Belt:}

It is made up of polyurethane material. The width of the belt is $100 \mathrm{~mm}$.Length of the belt is $1500 \mathrm{~mm}$. It is immersed in dusty particles up to $100 \mathrm{~mm}$.It withstand high temperature up to $180^{\circ} \mathrm{F}$.

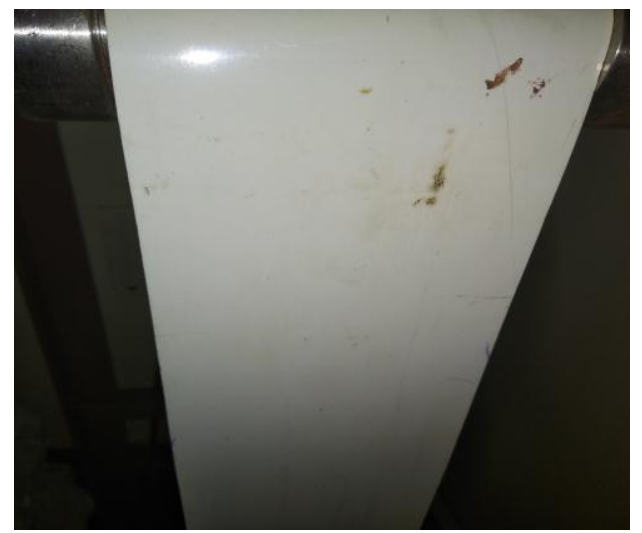

\subsection{Bearing:}

It is made up of cast iron. It is coated with aluminum coating. Main function of bearing is to rotate or hold the shaft. Each shaft contains 2 bearings at its end. Inner diameter is $45 \mathrm{~mm} \&$ Outer diameter is $59 \mathrm{~mm}$.

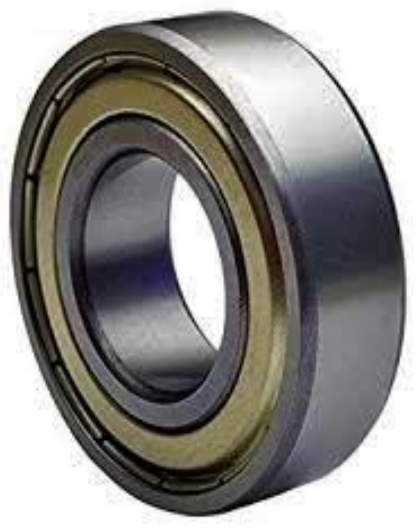

\subsection{Supporting Frame}

It is made up of mild steel. The length and width of the frame is $300 \mathrm{~mm}$ and $240 \mathrm{~mm}$. It supports the shaft, bearing and belt. The full weight of experimentation is balanced by supporting frame. and the belt, where the motor is also fixed on the frame
Table 1: detailed specifications of skimmer belt set-up.

\begin{tabular}{|c|c|c|}
\hline S.NO & PARTS & SPECIFICATION \\
\hline 1 & Shaft & $\begin{array}{l}\text { EN } 19 \text { Rod. Magnetic rod. Hard } \\
\text { material. }\end{array}$ \\
\hline \multirow[t]{2}{*}{2} & Belt & $\begin{array}{l}\text { Polyurethane material. Lenth- } \\
1500 \mathrm{~mm} \text {.Width- } \\
\text { 100mm.Temperature-180F }\end{array}$ \\
\hline & Bearing & Cast iron. Aluminu coated. \\
\hline 4 & Supporting Frame & $\begin{array}{l}\text { Made of mild steel. Lenth- } \\
300 \mathrm{~mm} \text {.Width-240mm }\end{array}$ \\
\hline
\end{tabular}

\section{Environmental Causes Due to Oil Spillage:}

\subsection{Ennore Port Oil Spill Blackens Chennai's Shoreline:}

Oil Spillage recently occurred in Ennore port on august 2017, INDIA. It caused due to accidental collusion of two oil tanker ships took place in the week hours of Saturday in Ennore port. But effects notice only on Sunday.

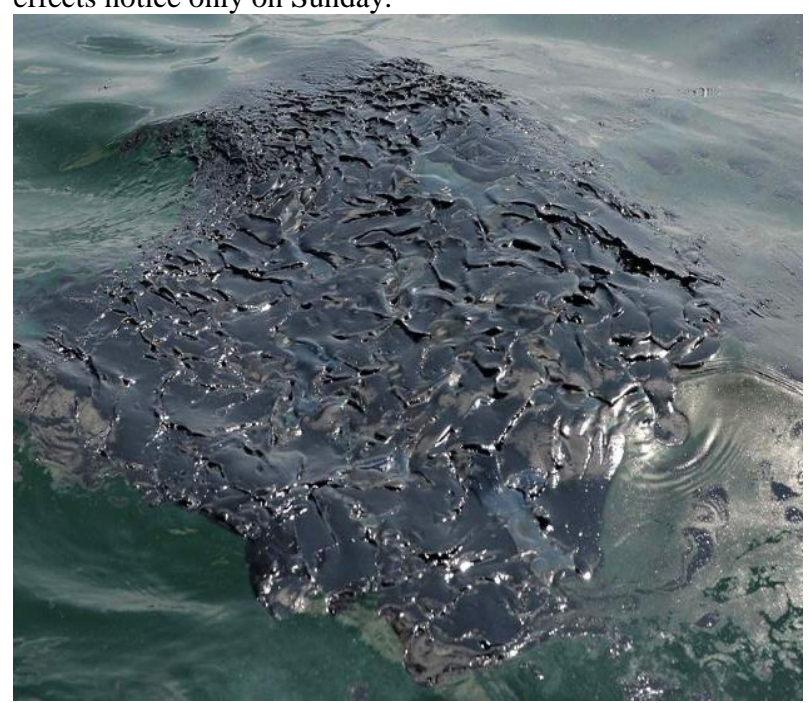

Fig.2: Ennore Port oil spill blackens Chennai's shoreline

\subsection{Oil Spills in the Ocean:}

Recently oil spill occurred at Gulf of Mexico due to an economical commercial effect on ocean resources extraction business (Encyclopedia Britannica news 2010). In last 5 years economic countries like USA, Canada, UK, Nigeria, China AND France. Faces problem of oil spillage.

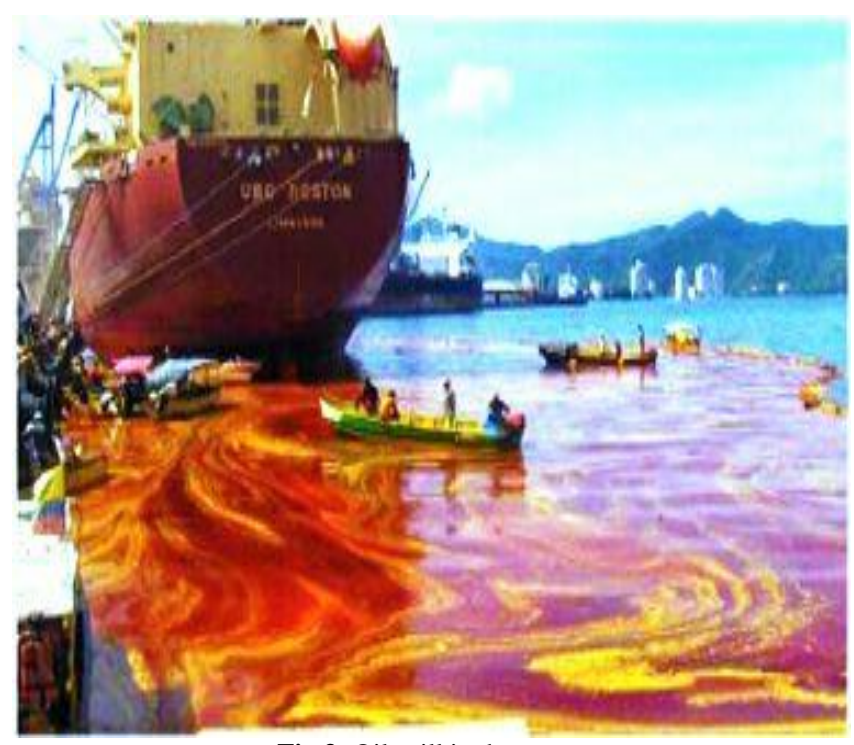

Fig.3: Oil spill in the ocean 


\subsection{Oil Spills in Sundarbans:}

Recently Oil Spillage Occurred Sundarbans Forest in Bangladesh, it caused severe damage to the animals and water resources. During 2014 Sundarbans oil spill was an oil spill occurred on 9 December 2014 at the Shela River in Sundarbans, Bangladesh, a UNESCO World Heritage site.The resources of forest were totally damaged.

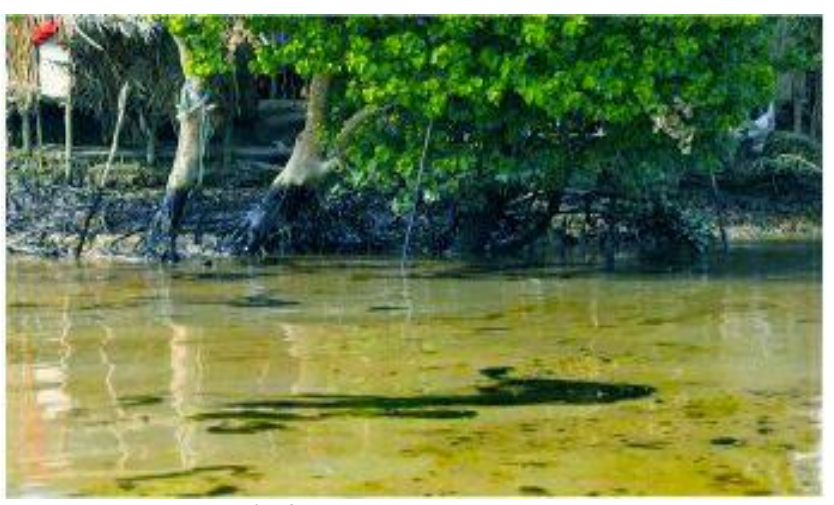

Fig.4: Sundarbans at Bangladesh

\section{Experimentation:}

The working of oil skimmer depends upon density difference between oil and water. The density of the oil is less than the density of the water. Hence when oil is mixed with water the oil floats on the surface of the water. It is rectangular frame when the motor is starts rotated with reduced speed with reduced speed \& belt start rotates. The belt is immersed in the contaminated water dust particles stick to the belt and scrapped oil is collected and the process is repeated. When the force is given to a shaft, the belt rotates over a Head shaft which is mounted on the shaft due to density. These oil sticks to the belt due to its oiliness property. The quantity of oil sticked to the belt is more because water has less oiliness property than oil. A scraper collects oil from moving belts and it is moved to the collected chamber thus process oil gets separated from coolant.

This returns up to $90 \%$ of the coolant in skimmed liquid and sends only waste oil in trash, saving tremendous cost due to almost full coolant recovery. A different set of experiments has been conducted by using the various oil and different materials of the belt to calculate oil recovery rate, oil recovery efficiency after separation. This project work discuss clearly about the oil separation.

\subsection{Applications:}

- Separating oil from water.

- Swimming pool sanitation.

- Cylindrical Grinding machine.

- $\quad$ Surface Grinders.

- Automats Milling Machine \& where coolant separation is necessary.

- Centre less grinding machine.

- $\quad$ Lathe machine.

\section{Conclusion:}

The present study is concerned to estimate the Oil Recovery Rate (ORR) and Oil recovery efficiency(ORE). The belt speed, belt incline angle and film thickness are the operating parameters. Speed of the belt cannot vary so it is to be improved by providing multispeed arrangement.
Water drops are collected simultaneously with the oil and this is to be reduced for better performance. Stirrer mechanism can be used to improve oil removal rate. Thus, various processes have been developed to remove oil from contaminated area by use of booms, dispersants and skimmers, oil water separator or by use of different kinds of sorbent materials. It is useful for small oil waste tanks in which it catches the oil floating on the surface of the tank.

As the results of experimental studies indicates the the design improvement of typical oil skimmers towards the belt shaft and use of skimmer belt significantly improve the oil recovery efficiency and also its becomes simpler.On further increasing the extensive research can improve the existing techniques and equipments to have better control for the oil recovery rate.

\section{Refernces:}

[1] Prof. Patel et.al. (2017) "Design and fabrication of oil skimmer" International Research Journal of Engineering and Technology, Vol. 04, issue 05, pp. 2282-2284.

[2] Prof. Suraj Nair et.al. (2017) "Design and Fabrication of disc type oil skimmer" International Journal for Scientific Research \& Development, Vol. 03, issue 04, pp.628-631.

[3] Naveen V Devanagoudar \& Hemanth Kumar TR.(2014) "Fabrication of oil separator in industry" International Journal of Science and Research, Vol. 03, issue 06, pp.56-57.

[4] Prof. Kuber K.H et.al. (2016) "Oil skimmer mechanism in sugar factory" International Journal of Mechanical and Industrial Technology, Vol. 03, issue 02, pp.174-176.

[5] Mamta Patel (2015) "Design and efficiency comparison of various belt type oil skimmer" International Journal of Science and Research, Vol .04, issue 01, pp.998-1002.

[6] Raju Merugu et.al. (2016) "Oil skimmer" International Journal of Research in Advent Technology, Vol. 04, issue 03, pp.53-55.

[7] Prof.A.S. Patil et.al (2015) "Endless belt type oil skimmer" International Journal of Recent Research in Civil and Mechanical Engineering, Vol. 02, issue 01, pp.95-100.

[8] V Sathiyamoorthy and T sekar (2016) "Optimisation of processing parameters in ECM of AISI 202 using multi objective genetic algorithm" International Journal of Enterprise Network Management 7 (2), 133-141. 